\title{
Argentine Danish: Semantic, syntactic and morphological differences from Standard Danish
}

\section{JAN HEEGÅRD PETERSEN \& KAROLINE KÜHL}

The term 'Argentine Danish' denominates the Danish language as spoken by descendants of the people who immigrated to Argentina between 1890 and 1930. It differs from 'Denmark Danish' in various ways, grammatically, phonologically and lexically. In this paper, we present seven case studies of these differences: lexical loans from Spanish, extended use of the Danish ere-derivation, semantic and syntactic changes in certain verb phrases, instances of pro-drop, instability in gender-marking and over-generalization of the phrase mere eller mindre. We discuss to what extent these features of Argentine Danish are due to influence from Spanish. The analyses are based on data from Corpus of South American Danish, which is part of the LANCHART corpus (University of Copenhagen). We suggest that the analyses provide the starting point for a discussion of whether Danish as spoken in Argentina can be viewed as a Danish variety in its own linguistic right. 